Proceedings

\title{
Power Generation from Bioenergy Crops by Technical and Economic Feasibility Assessment ${ }^{\dagger}$
}

\author{
Rubén Saint-Marc, José P. Paredes-Sánchez * and Jorge Xiberta-Bernat \\ Department of Energy, University of Oviedo, c/Independencia, 13, 33004 Oviedo, Spain; \\ rusaigu@gmail.com (R.S.-M.); jxiberta@uniovi.es (J.X.-B.) \\ * Correspondence: paredespablo@uniovi.es; Tel.: +34-985-104-305 \\ + Presented at the 2nd International Research Conference on Sustainable Energy, Engineering, Materials and \\ Environment (SEEME), Mieres, Spain, 25-27 July 2018.
}

Published: 1 November 2018

\begin{abstract}
Biomass offers opportunities to generate alternative sources of energy. The introduction of energy crops as a source of raw material for power generation is a challenge in Spain. The objective of this work is to know whether in a power plant the use of a natural resource as energy crops for electricity production is technically and economically feasible. In the energy field, a simulation model is performed, depicting the model plant previously defined, whose main input variables are, on one hand, the resource and on the other hand, the configuration of the energy conversion system. Forestry data together with energy plant investment and operation costs will also be input parameters for the economic model. With all the resources and the results of energy research, the appropriate economic model is applied to show the barriers of energy crops for electricity generation. The results show the difficulties in the use of energy crops.
\end{abstract}

Keywords: biomass; bioenergy; power

\section{Introduction}

Achieving sustainable energy supply that respects the environment is one challenge for our society today [1]. Global energy demand is increasing, and so is the environmental damage, due to the use of traditional energy sources. Biomass offers opportunities to create additional alternative sources of energy. The continued reliance on fossil fuels will make it very difficult to reduce emissions of greenhouse gases that contribute to global warming [2]. Bioenergy is one of the world's largest contributor of renewable energy. Biomass produces bioenergy; it is extracted from biological waste and organic raw material. Bioenergy in the past was largely viewed as a local commodity with local use of resources and consumption occurring domestically and is considered one of the most important sources for the future. The net biomass growing potential on the global land surface is 10 times more than the global feed, food, fiber, and bioenergy demands [3]. The bioenergy fosters energy crops and promotes rural development thanks to the availability of accessible technologies to a large extent developed and tested in the renewable energy context.

However, there is currently limited experience introduction of energy crops as a source of raw material for the generation of energy.

The objective of this work is to find out whether the use of a natural resource as energy crops for electricity production in a power plant is both technically and economically feasible with the technology available today and under the conditions established the current regulations in Spain, in which case energy crops could take a position as an energy source that meets the requirements described above. 


\section{Materials and Methods}

Three different fields are involved in the study of the global process of electricity generation from energy crops: first is forestry, which generates the resource to be used; then there is the field of energy that defines the technology to be applied to previously defined resources, and finally there is the normative scope defined by the renewable energy development policies through which the driving forces are established.

From the study of energy crops, taking poplar as a study species, in a planting density of 6666 feet per hectare and a 3-year cut shift, it is concluded that productivity depends on a large number of factors such as location, management and design of the plantation among others, and they cover a very wide range of values, but they have average values that are similar in all cases, therefore, a fork production between 10 and $40 \mathrm{t} /$ ha per year is defined which, in turn, will result in a fork of biomass generation costs.

To define the cost of biomass, the costs of planting, handling and harvesting are studied separately and, on the one hand, transport costs.

From the study of the different existing technologies, it is concluded that the use of energy crops for electricity using today's technology must be done through the direct combustion of biomass as it is the most mature and commercially available technology. In the energy field, the process is analogous, studying at first different existing technologies for biomass power generation, to finally define the technology to be used, (Rankine steam cycle) $[4,5]$. The thermodynamic cycle to be analyzed is defined first by technological analysis, which will be a Rankine cycle without reheating and with two extractions.

After determining the plant model the main costs thereof are defined: investment and exploitation. The investment and exploitation costs are obtained from each of their regressions, which have been defined from real data according to plant size and boiler technology (grate or fluid bed). They are determined for a range of plant sizes in power term (MW). The election of the optimum power will be one of the results of the study. Therefore, several plant sizes will be studied between 50 MW, upper limit marked by legislation for Special Regime facilities in RD 661/2007, and 10 MW, lower limit lower limit established by experience acquired on the economic viability of these plants [6].

Finally, in this industrial part, a simulation model of the configuration of the defined power generation plant is prepared. The model has as input fuel data (basically the Low Heating Value (LHV), associated with humidity); the boiler data analyzed (yield according to technology and humidity of the biomass) as well as general turbine data and other elements of the previously defined cycle. The result of this model gives rise to pairs of values that relate a quantity of biomass used with an amount of electricity produced for each type of boiler according to plant size and humidity of use of the biomass. The model has been validated through the simulation of real situations, where the difference between simulation results and reality has been less than $0.5 \%$ in terms of steam production, and $0.9 \%$ for electricity production, which gives an idea of the goodness of the model.

Regulation is the third group of previous knowledge, together with the forestry and industrial ones, that is necessary in order to perform the final economic analysis. The regulations of recent publication are studied (RD 413/2014 of 6 June, which regulates the activity of production of electrical energy from renewable energy sources, cogeneration and waste) and is compared with the previous one (Real Decree 661/2007, of 25 May, which regulates the activity of production of electric power in special regime), which did allow an interesting development of biomass for electrical use. From this study, we obtain the remuneration values to be introduced in the economic model that give rise to the income of the plant due to the sale of electricity.

A basic economic analysis is established whose results will be the economic parameters [6]. Internal Rate of Return (IRR) and Net Present Value (NPV) that will define the viability of the plant. This is accomplished by studying the process of biomass valorization, whereby the cost of this biomass, at the plant, is defined; from the definition of the generation plant to be used, through which the investment costs were established and the expenses and operating parameters; from the establishment of a simulation model that allows us to know the production of electricity from a certain amount of biomass and, finally, from the study of the regulations that mark the remuneration 
and, therefore, the income derived from the electricity sold. The economic model one will be applied to plants of various sizes and for different of biomass cost values.

\section{Results and Discussion}

The result of the economic analysis will allow defining, not only its profitability, but also the necessary areas, the prices of biomass and the minimum remuneration necessary to guarantee the operation of a plant associated to said profitability.

The results are represented graphically, since this allows for an easy and orderly visualization of the multitude of data analyzed (more than 1200 simulations have been carried out taking into account the variation of all the parameters studied) [6]. The profitability obtained can thus be appreciated intuitively. The graphs that represent the IRR indicate the value assured by RD 413/2014 (7.398\%) as the minimum objective value, as well as the minimum value required from the business point of view $(10 \%)$. The cost of the biomass represented in the graphs corresponds to the collection humidity (green $t$ ), to homogenize the data. Figure 1 shows a result of the simulation on average.

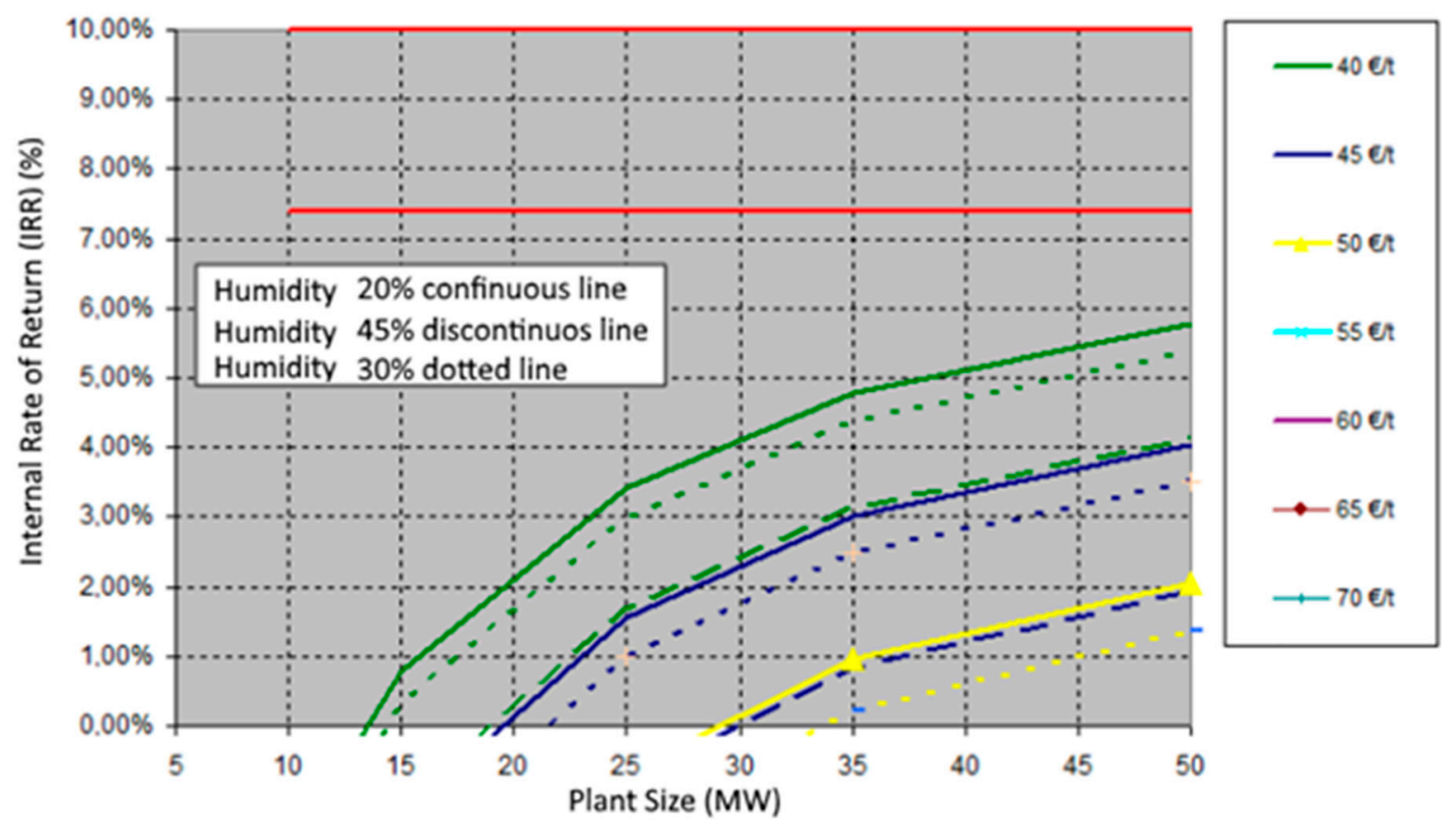

Figure 1. Example of the simulation results of the energy crops.

The fundamental parameter that marks the profitability of a project of this type is investment grade. The on considered in this study, which comes from real data, is high, which makes it possible for any improvement to bring profitability closer to the established objective. In order to achieve the objective profitability, with the cheapest biomass, it would be necessary for the investment to be much lower than the one considered.

The empirical findings from this study support investors who want to plan and strategize bioenergy investments in the scale of anticipated efficiency in the future [7]. To develop a sustainable bioenergy market the aim must be to make biomass economically viable by a combination of increases in yield and efficient processing methods [8].

\section{Conclusions}

Although Spain is rich in biomass resources, the technological developments in the field of biofuels and bio-energy are behind expectations. The previous regulation allows the viability of 25 MW plants for low biomass costs, between 40 and $45 € /$ green $t$ and, as the size of the plant grows, the necessary cost of biomass decreases. Thus, $50 \mathrm{MW}$ plants would have profitability with biomass of 
up to $50 € /$ green $t$. With current regulation, biomass costs must be much lower to ensure viability (Figure 1).

Given the above, the general conclusion reached is that the use of biomass from energy crops for the production of electricity under the current regulatory conditions is not viable. Development of new technologies, pathways and feedstock could be the future for an increased use of bioenergy in the energy mix. There is a vast potential market for the modern biomass technology. The focus of attention should be on a successful and sustainable integration of biomass crops.

Author Contributions: R.S.-M. performed the experiments; R.S.-M., J.P.P.-S. and J.X.-B. analyzed the data and wrote the paper.

Conflicts of Interest: The authors declare no conflict of interest.

\section{References}

1. Hussain, A.; Arif, S.M.; Aslam, M. Emerging renewable and sustainable energy technologies: State of the art. Renew. Sustain. Energy Rev. 2017, 71, 12-28. doi:10.1016/j.rser.2016.12.033.

2. Montoya, F.G.; Aguilera, M.J.; Manzano-Agugliaro, F. Renewable energy production in Spain: A review. Renew. Sustain. Energy Rev. 2014, 33, 509-531. doi:10.1016/j.rser.2014.01.091.

3. Rahman, M.M.; Mostafiz, S.B.; Paatero, J.V.; Lahdelma, R. Extension of energy crops on surplus agricultural lands: A potentially viable option in developing countries while fossil fuel reserves are diminishing. Renew. Sustain. Energy Rev. 2014, 29, 108-119. doi:10.1016/j.rser.2013.08.092.

4. Strzalka, R.; Schneider, D.; Eicker, U. Current status of bioenergy technologies in Germany. Renew. Sustain. Energy Rev. 2017, 72, 801-820. doi:10.1016/j.rser.2017.01.091.

5. Lecompte, S.; Huisseune, H.; van den Broek, M.; Vanslambrouck, B.; De Paepe, M. Review of organic Rankine cycle (ORC) architectures for waste heat recovery. Renew. Sustain. Energy Rev. 2015, 47, 448-461. doi:10.1016/j.rser.2015.03.089.

6. Saint-Marc, R. Use of Energy Crops for Electricity Generation. Technical-Economic Feasibility. Ph.D. Thesis, University of Oviedo, Oviedo, Spain, 9 November 2015.

7. Alsaleh, M.; Abdul-Rahim, A.S.; Mohd-Shahwahid, H.O. Determinants of technical efficiency in the bioenergy industry in the EU28 region. Renew. Sustain. Energy Rev. 2017, 78, 1331-1349. doi:10.1016/j.rser.2017.04.049.

8. Rowe, R.L.; Street, N.R.; Taylor, G. Identifying potential environmental impacts of large-scale deployment of dedicated bioenergy crops in the UK. Renew. Sustain. Energy Rev. 2009, 13, 271-290. doi:10.1016/j.rser.2007.07.008.

(c) 2018 by the authors. Licensee MDPI, Basel, Switzerland. This article is an open access article distributed under the terms and conditions of the Creative Commons Attribution (CC BY) license (http://creativecommons.org/licenses/by/4.0/). 